\title{
AUDITORY HYPERSENSITIVITY IN CHILDREN AND TEENAGERS WITH AUTISTIC SPECTRUM DISORDER
}

\author{
Erissandra Gomes ${ }^{1}$, Newra T. Rotta ${ }^{2}$, Fleming S. Pedroso ${ }^{3}$, \\ Pricila Sleifer ${ }^{4}$, Marlene C. Danesi ${ }^{5}$
}

\begin{abstract}
Objective: To verify if the clinical behavior of auditory hypersensitivity, reported in interviews with parents/caregivers and therapists/teachers of 46 children and teenagers suffering from autistic spectrum disorder, correspond to audiological findings. Method: The clinical diagnosis for auditory hypersensitivity was investigated by means of an interview. Subsequently, a test of the acoustic stapedial reflex was conducted, and responses to intense acoustic stimulus in open field were observed. Results: Of the 46 subjects, $11(23.9 \%)$ were clinically diagnosed as oversensitive to sound and only 2 showed discomfort when exposed to intense acoustic stimulus in open field. There was no statistically significant difference for the test of the ipsilateral acoustic stapedial reflex between the groups. Conclusion: Behavioral manifestations to sounds are not associated to hypersensitivity of the auditory pathways, but instead these are associated to difficulties in the upper processing, involving systems that usually are impaired in autistic spectrum patients, such as the limbic system.
\end{abstract}

KEY WORDS: autism, hypersensitivity, sound.

\begin{abstract}
Hipersensibilidade auditiva em crianças e adolescentes com transtorno do espectro autista
RESUMO - Objetivo: Verificar se o comportamento clínico de hipersensibilidade auditiva, relatado nas entrevistas com os pais/cuidadores e terapeutas/professores de crianças e adolescentes com transtorno do espectro autista, corresponde aos achados audiológicos. Método: O diagnóstico clínico para a hipersensibilidade auditiva foi investigado a partir do protocolo de entrevista. Após, foi utilizada a pesquisa do reflexo acústico estapédico e observadas as reações ao estímulo sonoro intenso em campo aberto. Resultados: Dos 46 sujeitos, $11(23,9 \%)$ foram diagnosticados clinicamente como hipersensíveis ao som, e somente 2 demonstraram desconforto quando expostos ao estímulo sonoro intenso em campo aberto. Não houve diferença estatisticamente significante para a pesquisa do reflexo acústico estapédico ipsilateral entre os grupos. Conclusão: As manifestações comportamentais aos sons não estão associadas à hipersensibilidade das vias auditivas, mas, sim, a dificuldades no processamento superior, envolvendo sistemas que comumente estão comprometidos nos pacientes do espectro autista, como o sistema límbico.
\end{abstract}

PALAVRAS-CHAVE: autismo, hipersensibilidade, som.

Leo Kanner was the first to describe a group of children suffering from autistic disturbances of affective contact, refered to the pattern of relationship among these children. The author also reported in his first description of autistic children the aversion some of these feeling towards certain sounds ${ }^{1}$. The current trend is to consider the continuum or spectrum, which includes autism as described by Kanner, but not only this, referring to three impairments - social interaction, communication, and imagination, which are related to each one dependently ${ }^{2-5}$. The autistic spectrum disorder includes, in addition to classic autism, Asperger's syndrome and pervasive developmental disorder not otherwise specified ${ }^{6-8}$. Autistic patients may present a change in the response to sensations, which is described as a sensory defense to tactile modalities (high sensitivity to touch or textures), as well as oral, visual (high sensitivity to light), and, mainly, acoustic modalities through a peculiar sensitivity to sounds ${ }^{5,9-11}$. Specifically concerning hypersensitivity to sounds, it is known that the terms auditory hypersensitivity, audiosensitivity, phonophobia, hyperacusis, and decreased tolerance to sounds

Universidade Federal do Rio Grande do Sul, Porto Alegre RS, Brazil (UFRS): ${ }^{1}$ Master in Medical Sciences: Pediatrics, Phonoaudiology Professor, Rede Metodista IPA, Porto Alegre RS, Brazil (IPA); ${ }^{2}$ Postdoctorship in Neurology, Pediatrics Department, UFRS; ${ }^{3}$ Doctor in Pediatrics, Pediatrics Professor, Universidade Federal de Santa Maria, Neurology Professor - IPA; ${ }^{4}$ Specialist, Phonoaudiology Professor, Audiology Department - Rede Metodista IPA; ${ }^{5}$ Master in Problems and Pathologies of Disability, Phonoaudiology Professor, IPA.Grant by CAPES

Received 24 November 2003, received in final form 17 March 2004. Accepted 6 May 2004.

Dra. Erissandra Gomes - Rua Duque de Caxias 955/406 - 90010-282 Porto Alegre RS - Brasil. E-mail: erifono@hotmail.com 
have been used as synonyms in similar contexts ${ }^{12,13}$. Some authors report that auditory hypersensitivity may appear in three ways: hyperacusis, phonophobia, and increased dysacusis ${ }^{12,14-16}$. The pathogenesis of auditory hypersensitivity is still unknown, with several potential causes existing ${ }^{13,17-19}$.

Autistic individuals are hard to evaluate by means of subjective tests. The clinical use of otoacoustic emissions in autistic children is a non-invasive, objective method, which is accurate in respect to the level of stimulation and frequency aimed in assessing the peripheral auditory system in patients presenting unusual responses to audiometric procedures as a consequence of their behavioral and interactive characteristics ${ }^{20-26}$. The study of the acoustic stapedial reflex is also suitable for hard-to-test patients, as it leads to objective results ${ }^{24-27}$. The loudness discomfort level test is used as an audiologic test to detect hypersensitivity, since it is a method usually utilized to determine the level of tolerance to intense sound ${ }^{13,18}$

The purpose of this study was to verify if the clinical behavior of auditory hypersensitivity, reported in interviews with parents/caregivers and therapists/teachers of children and teenagers with autistic spectrum disorder, corresponds to the audiologic findings (test of acoustic stapedial reflex and observed responses to intense acoustic stimulus in open field) and ascertain, if other types of stimuli lead to oversensitive responses as well.

\section{METHOD}

Population under study - Children and teenagers with autistic spectrum disorder, who regularly came for clinical care at the IPA Clinic; clinical and pedagogical care at Teach Novo Horizonte Center, at Kinder and CADEP's Autism Nucleus; and pedagogical assistance at Lucena Borges Municipal School. The subjects of this population were subjected to clinical and/or pedagogical follow-up at the institutions they belonged to. Inclusion criteria - every child and teenager at ages ranging from 5 to 20 years who attended the aforementioned institutions and fit in the autistic spectrum disorder according to DSM IV criteria. Exclusion criteria - children and teenagers with autistic spectrum disorder whose parents did$n$ 't sign the consent form; those whose audiological evaluation showed signs indicative of hearing loss; and those who didn't complete all evaluations.

Data collection was carried out by examination procedures. All children and teenagers in the sample were evaluated by the assistant neurologist, who in agreement with the therapist confirmed the autistic spectrum disorder diagnosis. After confirmation of the diagnosis, the children and teenagers were evaluated by the same phonoaudiologist at IPA Clinic, specialized in audiology, with the purpose of excluding the ones suffering from hearing loss and evaluating the audiological findings. Distortion-product otoacoustic emissions were carried out in an acoustic booth, with internal noise lower than $30 \mathrm{~dB}$, using the Hort Mann-Neuro-Otometrie software (made in the USA), connected to an AmDis-OEA software and a microphone-probe, which is inserted into the external acoustic meatus by means of a flexible rubber (used to seal the external acoustic meatus). For the measurements of acoustic immittance, the Impedance Audiometer AT22 t (Interacoustics, Germany) was used, and the acoustic stapedial reflexes were studied at frequencies of $500 \mathrm{~Hz}, 1000 \mathrm{~Hz}, 2000 \mathrm{~Hz}$ and $4000 \mathrm{~Hz}$ in both ears, with final recording at dBNPS. For the study of observed responses to intense acoustic stimulus in open field, the Clinical Audiometer AC30 (Interacoustics, Germany) was used. The acoustic stimulus used was a warble at a $90 \mathrm{~dB}$ mean intensity, between frequencies of $500 \mathrm{~Hz}$ to $6000 \mathrm{~Hz}$, conducted in an acoustic booth, in which the stimulus was emitted by an Interaudio 1000XL speaker (made in Ireland). All equipment was properly calibrated.

The diagnosis for auditory hypersensitivity, by means of the clinical characteristics for this event, was investigated using an interview with parents/caregivers and the procedure for auditory hypersensitivity aimed at therapists/teachers, which were conducted in the clinical-therapeutic setting of every child. The work was overseen by the supervisor and co-supervisor.

The statistic program used for the analyses was SPSS (version 11.0). Analyses of frequency were performed, the mean and standard-deviation were calculated, and Fisher's exact test and the Kappa coefficient were used. The estimated rates of hypersensitivity were achieved by the calculation of the $95 \%$ confidence interval. The significance level was set at $5 \%(\alpha=0.05)$.

Ethic aspects - The responsible for the institutions involved in the study signed a consent form. The parents and/or responsible were properly enlightened as to the study goals, and only the cases in which these signed informed consent form were included. This project was approved by the IPA College Ethics Committee and by the Committee of Research and Ethics in Health of Hospital de Clínicas de Porto Alegre.

\section{RESULTS}

The data from 46 children and teenagers with autistic spectrum disorder that attended different institutions in Porto Alegre were analyzed. Of these, 39 (84.8\%) were males. Ages range was 5 to 19 years (mean age 10.85 years). As regards therapeutic support, $30(65.2 \%)$ were undergoing phonoaudiological treatment, $8(17.4 \%)$ physiotherapeutic treatment, $3(6.5 \%)$ psychological treatment, $4(8.7 \%)$ psychiatric treatment, $12(26.1 \%)$ 
Table 1. Presence of hypersensitivity in 46 Autistic patients.

\begin{tabular}{lccc}
\hline & $\mathrm{n}$ & $\%$ & $95 \% \mathrm{Cl}$ \\
\hline Sound & 11 & 23.9 & $13.1-39.1$ \\
Light & 6 & 13 & $5.4-27$ \\
Touch & 11 & 23.9 & $13.1-39.1$ \\
\hline
\end{tabular}

$\mathrm{Cl}$, confidence interval.

occupational therapy, and $5(10.9 \%)$ were undergoing other types of treatment.

As for hypersensitivity, 11 were oversensitive to sound, 6 oversensitive to light, and 11 oversensitive to touch (Table 1). In this sample, there was a report on insensitivity to pain in 19 cases $(41.3 \%)$.

Seeking a correlation between the different types of sensoriperceptual abnormalities, no correlation of hypersensitivity to sound with the other types of hypersensitivity was observed (Table 2). Only a correlation between abnormal response to light and touch occurred.

Of the 46 subjects, 11 (23.9\%) are literate, and $28(60.9 \%)$ possess verbal language. Of the 11 literate subjects, 4 (36.4\%) are oversensitive to sound, while among the 35 illiterate, $7(20.0 \%)$ are oversensitive to sound. Of the 28 presenting verbal language, $8(28.6 \%)$ are oversensitive to sound, and of the 18 without verbal language, $3(16.7 \%)$ are oversensitive to the same stimulus.

Among the 11 oversensitive to sound, 2 (18.2\%) demonstrated discomfort when exposed to intense acoustic stimulus in open field; however, of the 35 remaining, none demonstrated a discomfort response. Such findings show a borderline significance $(p=0.053)$. Of the 11 subjects that were oversensitive to sound, $10(91 \%)$ showed the associated motions of putting their hands on the ears, and of the 35 non-oversensitive, only 2 (5.7\%) performed this movement $(p<0.001)$.

The results from the ipsilateral acoustic stapedial reflex test are shown in Table 3.

\section{DISCUSSION}

There was been several reports highlighting abnormal responses to sensoriperceptual stimuli, such as visual, tactile, smell-related, taste-related and, most notably, auditory stimuli $i^{5,10,11,28}$. The findings from our study showed a prevalence of hypersensitivity to sound and touch. Regarding the auditory aspect, the rate of hypersensitivity to sound disclosed in this study was $23.9 \%$, considering this a clinical characteristic described by parents/care-
Table 2. Correlation between sensoriperceptual abnormalities in 46 autistic patients.

\begin{tabular}{cccc}
\hline & sound & light & touch \\
& OR & OR & OR \\
Cl95\% & Cl95\% & Cl95\% \\
& Value-p & Value-p & Value-p \\
\hline light & 4.0 & - & - \\
& $(0.7-23.7)$ & & \\
& 0.1 & & - \\
touch & 4.0 & 9.4 & \\
& $(0.9-17.6)$ & $(1.4-62.0)$ & 0.4 \\
& 0.1 & 0.02 & $(0.1-2.0)$ \\
pain & 1.3 & 3.3 & 0.32 \\
& $(0.3-4.9)$ & $(0.5-20.5)$ & 0.21 \\
\end{tabular}

$\mathrm{OR}$, odds ratio; $\mathrm{Cl}$, confidence interval

givers and therapists/teachers. This result is in agreement with the findings of literature that use the clinical method is refered as seing a common feature to children and teenagers with autistic spectrum disorder ranging from $15 \%$ to $40 \% 21,22$. Although these results are widely mentioned, few one studies are concerned to reporting rates.

Of the 11 children and teenagers clinically diagnosed as hypersensitive to sound, only 2 showed discomfort when exposed to intense acoustic stimulus in open field ( $90 \mathrm{~dB}$ - warble). The statistic significance for this datum was borderline. The only study available for discussion was the one that identified $18 \%$ as oversensitive to a $70 \mathrm{db}$ click stimulus ${ }^{20}$. The borderline significance suggests that perhaps this difference really may be achieved in a larger number of cases. The observation of behavioral responses to intense acoustic stimulus in open field was the method used to determine the tolerance to the respective stimulus, since the use of the loudness discomfort level test is not feasible in autistic patients as it demands patient collaboration ${ }^{13,18}$.

In this study, there was no difference between the 2 groups studied when the results from the test of the ipsilateral acoustic stapedial reflex were analyzed. The studies dealing with hypersensitivity to sound in children and teenagers with autistic spectrum disorder suggest that there is some difference between patients and controls, but the authors themselves point out to the fact that the difference is not significant ${ }^{13,18,29}$. It urges to underscore the importance of this test for autistic children and teenagers, as it is an objective test indicated 
Table 3. Findings from the ipsilateral acoustic stapedial reflex test in 46 Autistic patients.

\begin{tabular}{|c|c|c|c|c|c|}
\hline & $\begin{array}{c}\text { OS } \\
(n=11) \\
\text { mean } \pm s d\end{array}$ & $\begin{array}{c}\text { NOS } \\
(n=35) \\
\text { mean } \pm s d\end{array}$ & $\begin{array}{c}\text { Difference } \\
\text { between } \\
\text { means }\end{array}$ & $\begin{array}{c}\mathrm{Cl} \\
95 \%\end{array}$ & Value-p \\
\hline \multicolumn{6}{|l|}{ Right } \\
\hline $500 \mathrm{~Hz}$ & $\begin{array}{c}95 \pm 11.2 \\
(n=7)\end{array}$ & $\begin{array}{c}98.4 \pm 9 \\
(n=28)\end{array}$ & -3.39 & $(-11.5-4.7)$ & 0.39 \\
\hline $1000 \mathrm{~Hz}$ & $\begin{array}{c}97.8 \pm 6.2 \\
(n=9)\end{array}$ & $\begin{array}{c}100.5 \pm 8.5 \\
(n=31)\end{array}$ & -2.71 & $(-8.9-3.5)$ & 0.38 \\
\hline $2000 \mathrm{~Hz}$ & $\begin{array}{c}100 \pm 8 \\
(n=8)\end{array}$ & $\begin{array}{c}102.8 \pm 8.4 \\
(n=30)\end{array}$ & -2.83 & $(-9.5-3.9)$ & 0.39 \\
\hline $4000 \mathrm{~Hz}$ & $\begin{array}{c}94.4 \pm 9.8 \\
(n=9)\end{array}$ & $\begin{array}{c}94.3 \pm 7.2 \\
(n=27)\end{array}$ & 0.19 & $(-6.0-6.3)$ & 0.95 \\
\hline \multicolumn{6}{|l|}{ Left } \\
\hline $500 \mathrm{~Hz}$ & $\begin{array}{c}97.8 \pm 7.1 \\
(n=9)\end{array}$ & $\begin{array}{c}100.6 \pm 6.5 \\
(n=27)\end{array}$ & -2.78 & $(-8.0-2.4)$ & 0.29 \\
\hline $1000 \mathrm{~Hz}$ & $\begin{array}{c}100.6 \pm 10.4 \\
(n=9)\end{array}$ & $\begin{array}{c}100.8 \pm 8.7 \\
(n=30)\end{array}$ & -0.28 & $(-7.3-6.7)$ & 0.94 \\
\hline $2000 \mathrm{~Hz}$ & $\begin{array}{c}105 \pm 7.5 \\
(n=9)\end{array}$ & $\begin{array}{c}102 \pm 7.4 \\
(n=28)\end{array}$ & 3.04 & $(-2.7-8.8)$ & 0.30 \\
\hline $4000 \mathrm{~Hz}$ & $\begin{array}{c}93.1 \pm 5.9 \\
(n=8)\end{array}$ & $\begin{array}{c}97.4 \pm 6.3 \\
(n=27)\end{array}$ & -4.28 & $(-9.3-0.8)$ & 0.09 \\
\hline
\end{tabular}

for patients that usually are hardly to be tested. The use of the acoustic stapedial reflex test for hyperacusic patients, when differentiating these from the ones with phonophobia, has been criticized. Hyperacusis is an abnormal response that occurs in the auditory pathways as a result from exposure to a certain sound level, which causes reduction in the tolerance thereof, whereas phonophobia is an abnormal response from the limbic and autonomic systems, without auditory abnormality, but originating from an increase in the connections between the auditory and limbic systems ${ }^{16}$.

Usually the emotional factor can magnify the global stimulation and cause, in some person, an enhancement in the perception of visual, auditory, smell and/or painful stimuli. Hypersensitivity involves the limbic system, and this system usually shows abnormalities in autistic subjects. When a sound elicits abnormal responses, the result is the establishment of a subconscious reflex response with automatic and invariable activation of the limbic and autonomic nervous systems. With respect to the pathophysiological mechanism of hearing, the conscious perception of sound occurs only when the stimulus reaches the auditory cortex; however, the perception of intensity is not defined by sound intensity, but also by its meaning and associations ${ }^{15,30}$.

The correlation observed between hypersensitivity to sound and the motions of placing the hands on the ears may result from the stimulation of the autonomic nervous system and the triggering of protective reflexes. There is a link between perceptual abnormalities and behaviors of stereotypy, fixations, and obsessions ${ }^{9}$.

The results from this study show that the behavioral manifestations to sounds are not associated to hypersensitivity of the auditory pathways, but rather to difficulties in the upper processing at the level of the cerebral cortex, involving systems that usually are impaired in autistic spectrum patients, such as the limbic system. Identical results occur with other changes in sensitivity and their associated behaviors, as fear and reality distortions, which are complex interactions originated from upper processings, instead of specific hypersensitive pathways. 
Acknowledgments - We would like to thank the following institutions for their collaboration with the study: IPA Clinic, Teach Novo Horizonte Center, Kinder, CADEP Autism Nucleus, and Lucena Borges Municipal School.

\section{REFERENCES}

1. Kanner L. Autistic disturbances of affective contact. Nerv Child 1943;2:217-250

2. Wing L, Gould J. Severe impairments of social interaction and associated abnormalities in children: epidemiology and classification. J Autism Dev Disord 1979;9:11-29.

3. Watherhouse L, Morris R, Allen D, et al. Diagnosis and classifications in autism. J Autism Dev Disord 1996;26:59-88.

4. Wetherby A, Prizant B. Introduction to autism spectrum disorders. In Wetherby A, Prizant B. (EDS) Autism spectrum disorders: a transactional developmental perspective. Baltimore: Paul Brooks, 2001:1-7.

5. Gadia CA, Tuchman RF. Manejo de los niños con trastornos del espectro autista. Rev Neurol 2003;36:166-173.

6. Tanguay PE, Robertson J, Derrick A. A dimensional classification of autism spectrum disorder by social communication domains. J Am Acad Child Adolesc Psychiatry 1998;37:271-277.

7. Lord C, Levental B, Cook E. Quantifying the phenotype in autism spectrum disorders. Am J Medic Genet 2001; 105:36-38.

8. Bertrand J, Mars A, Boyle C, Bove F, Yearging-Allsopp M, Decoufle P. Prevalence of autism in a United States population: the Brick Township, New Jersey, investigation. Pediatrics 2001;108:1155-1161.

9. O'Neill M, Jones RS. Sensory-perceptual abnormalities in autism: a case for more research? J Autism Dev Disord 1997;27:283-293.

10. Grandin G, Scariano MM. Uma menina estranha: autobiografia de uma autista. [trad. Sérgio Flaksman]. São Paulo: Companhia das Letras, 1999.

11. Kern JK. The possible role of the cerebellum in autism/PDD: disruption of a multisensory feedback loop. Med Hypot 2002;59:255-260.

12. Anari M, Axelson A, Eliasson A, Magnusson L. Hypersensitivity to sound: questionnaire data, audiometry and classification. Scand Audiol. 1999;28:219-230.

13. Katzenell U, Segal S. Hiperacusis: review and clinical guidelines. Oto Neurotol 2001;22:321-326.
14. Phillips DP, Carr MM. Disturbances of loudness perception. J Am Acad Audiol 1998;9:371-379.

15. Sanchez T, Pedalani M, Bento R. Hiperacusia: artigo de revisão. Arq Fund Otorrinol 1999;3:184-188.

16. Jastreboff PJ. Hiperacusis: review and clinical guidelines - invited comments. Oto Neurotol 2001;22:326-327.

17. Nigam A, Samuel P. Hyperacusis and Willians syndrome. J Laryngol Otol 1994;108:494-496.

18. Brandy W, Lynn J. Audiologic findings in hyperacusic and nonhiperacusic subjects. Am J Audiol 1995;4:46-51.

19. Bingham P, Clancy RR. Segredos em neuropediatria. In Polin R, Ditmar M (eds). Segredos em Pediatria. Porto Alegre: Artmed, 2001: 275-277.

20. Rosenhall U, Nordin V, Sandstrom M, Ahlsen G, Gillberg C. Autism and hearing loss. J Autism Dev Disord 1999;29:349-357.

21. Calderón-González R, Santillán-Flores A, Rodríguez-Cavazos O, PomarSerradell A, Gutiérrez-Treviño M, Díaz-Muraira M. Autismo infantil: II. estudio del lenguaje en 27 niños. Bol Med Hosp Infant Mex 1988;45:79-83.

22. Edelson SM. Implications of sensory stimulation in self-destructive behavior. Am J Ment Defic 1984;89:140-145.

23. Grewe TS, Danhauer JL, Danhauer KJ, Thornton AR. Clinical use of otoacoustic emissions in children with autism. Int J Pediatr Otorhinolaryngol 1994;30:123-132.

24. Katz J. Tratado de audiologia clínica. São Paulo: Manole, 1999.

25. Lonsbury-Martin B, Martin G, Telischi F. Emissões otoacústicas na prática clínica. In: Musiek \& Rintelmann (eds). Perspectivas atuais em avaliação auditiva. São Paulo: Manole, 2001:163-192.

26. Wilber L A. Audiometria tonal laminar: via aérea e via óssea. In Musiek \& Rintelmann (eds). Perspectivas atuais em avaliação auditiva. São Paulo: Manole, 2001:1-20.

27. Wilson R, Margolis R. Reflexo acústico. In Musiek \& Rintelmann (eds). Perspectivas atuais em avaliação auditiva. São Paulo: Manole, 2001: 127-162.

28. Bettison S. The long-term effects of auditory training on children with autism. J Autism Dev Disord 1996;26:361-374.

29. Gordon A. Abnormal middle ear muscle reflexes and audiosensitivity. Br J Audiol 1986;20:95-99.

30. Bauman M. Brief report: neuroanatomic observation of the brain in pervasive developmental disorders. J Autism Dev Disord 1996;26:199-203. 